Alma Mater Studiorum - Università di Bologna DEPARTMENT OF ECONOMICS

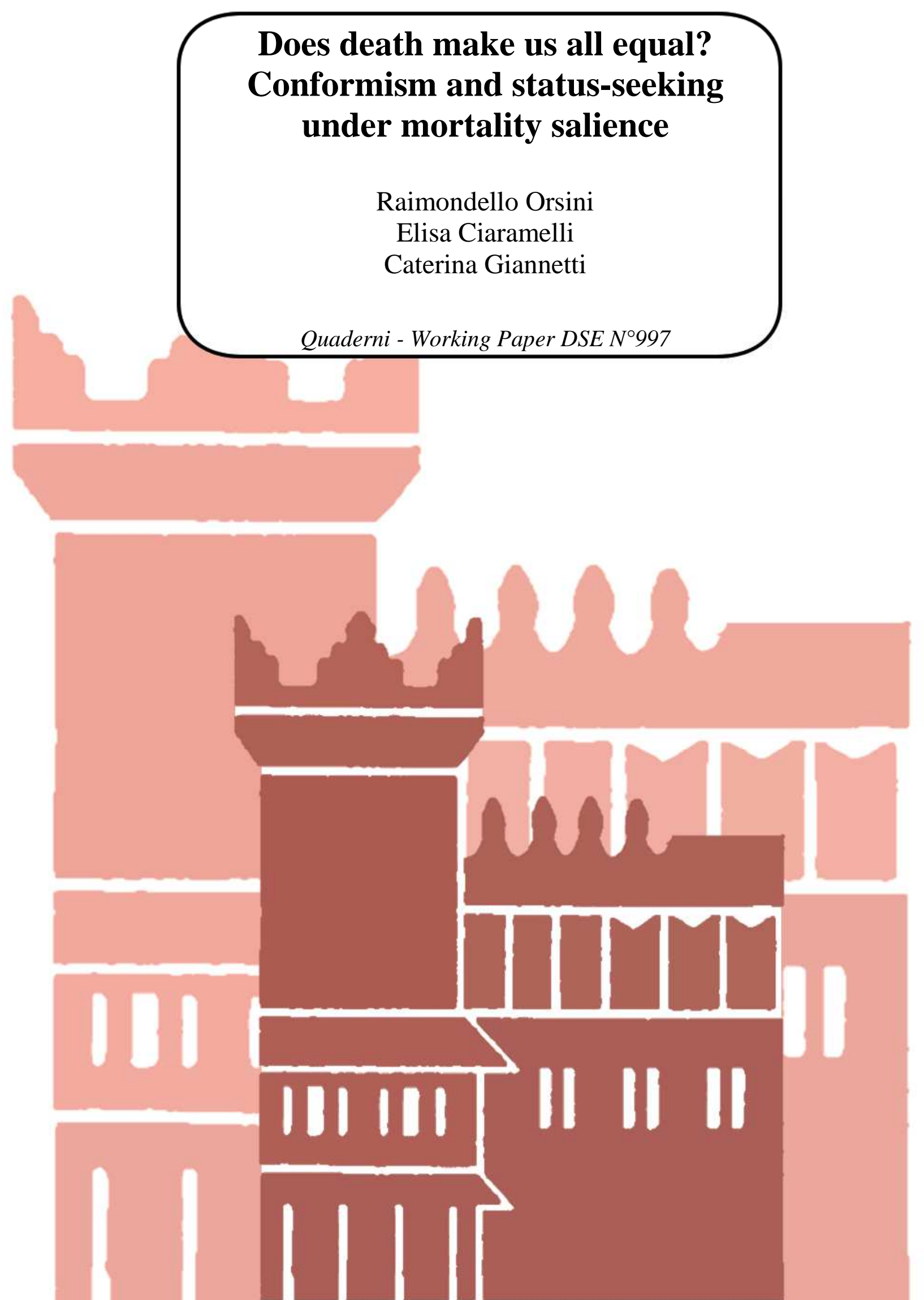




\title{
Does death make us all equal? Conformism and status-seeking under mortality salience
}

\author{
Raimondello Orsini ${ }^{1}$ Elisa Ciaramelli ${ }^{2}$ Caterina Giannetti ${ }^{3}$ \\ 18th March 2015
}

\begin{abstract}
The thought of one's own death induces anxiety and threatens self-esteem. According to Terror Management Theory, to reduce this existential threat individuals typically embrace their cultural worldview, and seek for an increase in self-esteem and status by improving their productivity. Within an experimental economy setting, this paper investigates the effect of Mortality Salience (MS) on individual productivity, using for the first time a real-effort task where the economic incentive is to not perform. We investigated whether the improvement in productivity was significantly driven by self-esteem or status seeking, providing either private feedback alone or, additionally, public feedback. Always controlling for participants' individual susceptibility to the MS induction, our results indicate that subjects generally tend to be more sensitive to in-group conformity under MS compared to a control (Music) induction condition. That is, they initially improve their performance to enhance self-esteem, but then homologate to average performance levels, consistent with the incentive not to perform. However, for a subset of less materialistic participants, with strong susceptibility to MS, performance levels constantly improved along the task.
\end{abstract}

Keywords: Terror Management Theory, Self-esteem, Status, Feedback

JEL Classification: C91; C92; D12

\footnotetext{
${ }^{1}$ Corresponding author. University of Bologna. Department of Economics. Strada Maggiore, 45. 40125 Bologna. Tel: +39.0512091281. Email: raimondello.orsini@unibo.it

${ }^{2}$ Department of Psychology. University of Bologna. Email: elisa.ciaramelli@unibo.it

${ }^{3}$ Luiss School of European Political Economy. Email: cgiannetti@luiss.it

This research has benefited from discussions with a number of people. We would like to thank Maria Bigoni, Fabio Galeotti, Alexia Gaudeul, Antonino Rotolo as well as participants at SONIC meeting and internal seminar at University of Bologna. Financial support from the University of Bologna - FARB research project "Mortality salience, conformitá a norme giuridiche e sociali, comportamenti economici: modelli teorici e metodologie sperimentali" is gratefully aknowledged.
} 
Man is but a reed, the most feeble thing in nature; but he is a thinking reed. The entire

universe need not arm itself to crush him. A vapour, a drop of water suffices to kill him. But, if the universe were to crush him, man would still be more noble than that which killed him, because he knows that he dies and the advantage which the universe has over him; the universe knows nothing of this.

Blaise Pascal, Pensées.

\section{Introduction}

As humans, we are all aware that our life will come to an end, and we all have experienced - at least once in our life -the terror accompanying the thought of our death. According to Terror Management Theory (TMT), dating back to the work of Ernst Becker (1973), the fear of death has a unique effect on human life due to its potential to induce overwhelming anxiety and threaten our self-esteem. According to Becker (1973), to avoid living in a state of paralyzing terror, individuals seek to deny this threat and bolster self-esteem, by conforming to a variety of cultural belief systems that help reducing existential insecurity. This view is consistent with that held by several philosophers, such as Kierkegaard, Nietzsche, Rank, Sartre, and Tillich (see Arndt et al. (2004a)). Cultural beliefs are socially constructed and are shared by groups of people in a certain place and at a certain time. Although faith in these cultural beliefs is an essential means by which individuals afford protection from existential insecurity, it is not itself sufficient. Individuals, indeed, also need to feel that they are significant contributors to their vision of a meaningful universe (Becker (2007) ); in other words, they need to obtain - and sustain - self-esteem. TMT hypothesizes that when the mortality salience increases, individuals express stronger belief in their own cultural worldviews, for example by focusing on material values (e.g. consumption, brand connections), and - to the extent that self-esteem provides protection against concerns regarding death - should increase those social behaviours that result in feelings of self-worth (e.g. conspicuous consumption, work overtime). Substantial evidence confirms the reliability of this theory across a variety of measures, countries, and demographic samples (seeArndt et al. (2004b); Solomon et al. (2004)).

Despite the increasing psychological evidence in favor of TMT, however, the association of mortality salience and economic behaviour has not been fully investigated yet. In this context, for example, previous psychological research has investigated whether the fear of death instigates subjects' identification with a cultural worldview in which individuals purchase symbolic goods to reflect their own value (see, for example, Arndt et al. (2004b)). To the best of our knowledge, however, these studies do not rely on incentive-compatible mechanisms (e.g. do not use cash to motivate subjects true-telling), which are instead at the core of the experimental research in economics, and are more suitable to mimic real-world incentives and capture individual materialism. 
In this experiment, we test TMT in an experimental economic setting by paying subjects to perform a real-effort task. More specifically, the aim of this research is to study the effect of mortality salience on individuals' effort to gain self-esteem and social status when the economic incentives are clear, and direct individuals to exert no effort. To this aim, similar to Charness et al. (2013), we chose to implement a flat-wage scheme, which implies that subjects received a fixed amount of money regardless of their performance in the real-effort task. This way, we isolate the effect of ranking from the one associated to the monetary benefits in other schemes (such as piece-rate), as subjects have no economic incentives to exert a positive effort. Moreover, we can also avoid the contradictory effects that money can have when mortality salience increases (see Jonas and Greenberg (2013)). We define status as the individual's relative standing in a peer-group (see Charness et al. (2013)) and induce it in the laboratory by providing subjects with public feedback information on their relative performance (i.e. their rank). To induce the effect on self-esteem, we run treatments in the absence of the rank observability by others as subjects receive rank information only privately.

The main advantage of our design is thus to combine an incentivized real effort task with the priming on death-related thoughts. Exerting effort to gain self-esteem and social status when this goes against economic incentives would be a clear demonstration of how much individuals pay to protect themselves from existential insecurity and its costs. ${ }^{1}$

Our experiment consists in a $2 \times 2$ treatments. The base setting is structured as follows: each period participants were randomly allocated to groups of three, and performed a real-effort task (i.e. summations). We provided individuals with either private or public feedback on ranking (i.e. how they performed in comparisons with their peers). In the mortality-salience treatments, individuals were reminded of their own death before starting the experimental game, while in the Music treatments individuals are asked to describe their emotion while listening to classical music. $^{2}$

In line with psychological research, we expected to find a greater quest for self-esteem and status after mortality salience induction, resulting in a increase in performance in the real-effort task. We also expected a stronger effect in case of public feedback, as the observability by others should affect both self-esteem and status. Note that, from an economic point of view, under the flat-wage scheme in no condition should subjects exert an effort above the minimum (i.e. zero). However, to the extent that sensitivity to the flat-wage may increase as a result of the augmented materialism (see Kasser and Sheldon (2000), Arndt et al. (2004a)), participants'quest for self-esteem may be offset by the economic incentives to perform. We additionally hypothesized that the effect of MS induction would be reinforced when subjects are publicly informed about

\footnotetext{
${ }^{1}$ As such, it is not an option to not pay our subjects.

${ }^{2}$ Several studies have also proved that the effects of Mortality Salience remain with an alternative (negative) control topic (such as dental pain), suggesting they go beyond negative mood. See Arndt et al. (2004a), and later on footnote 8 .
} 
their ranking, as the drive of status-seeking is added to the drive of self-esteem.

To foreshadow the results, our predictions were partially confirmed: we found that when primed with death-related thoughts, individuals tended to perform more homogeneously, that is, to conform to others' behavior. That is, the distributions of the number of points under mortality salience have substantially lower variability than the distributions of the number of points under the control priming topic. For a subset of (less materialistic) participants, however, we constantly observed a higher level of performance in the mortality salience compared to the control treatments as if for this group of subjects, the driver of self-esteem was never overtaken by the economic incentive to play the minimum effort. ${ }^{3}$ This held when subjects were provided with both private and public feedback, though public feedback had no additional effect in the mortality salience treatment, as if intrinsic motivation of individuals, and not individuals' need for public recognition, mainly drove subjects' behaviour. Importantly, we found that these effects held when controlling for a number of individual characteristics, such as age, sex, mathematical ability, as well as personal and social development.

The remainder of the paper is structured as follows: Section 2 introduces Terror Management Theory, Section 3 presents the review of the experimental economics literature on statusseeking, while Section 4 discusses the main characteristics of our experimental design. Section 5 presents the results and Section 6 summarizes and concludes our argument.

\section{Terror Management Theory}

A substantial body of evidence illustrates that the thoughts of one's own death affect a wide range of human activities, including creativity, risk-taking, close relationships, sexual attitudes, identification with groups, nationalism and prejudices. For example, previous research has shown that after mortality-salience induction, individuals exhibit enhanced reactions towards those who break legal, social and cultural norms, a greater sense of social affiliation - from social group identity to patriotic identification (Greenberg et al. (1997)), and a more materialistic and greedy behavior (Kasser and Sheldon (2000)). Individuals also become more sensitive to famous luxurious brands and change their subjective evaluation of time (Simon et al. (1997)).

According to Terror Management Theory (Arndt et al. (2004a)), individuals gain protection from death-related fear through culture, which enables them to feel "valuable contributors to a meaningful universe", and therefore, arguably more tightly tied to it. More specifically, in order to provide an anxiety buffer, an effective terror management requires two ingredients:

1. faith in a meaningful conception of reality (the cultural worldview);

2. belief that one is meeting the standard of value prescribed by that worldview (self-esteem).

\footnotetext{
${ }^{3}$ As the task is sufficiently easy, it is reasonable to assume that performance and effort go in the same direction. We nevertheless control for individual ability. For a similar setting see Charness et al. (2013).
} 
Since these two ingredients protect from potential terror, people are motivated to maintain faith in their cultural worldviews and satisfy the associated standards of value. Developmental psychology postulates that self-esteem and recognition by others are substitutes of love and protection by parents. The child meets the parents' standards to assure himself protection, while conditional disposition of affection is the tool parents use to get a conform child who behaves appropriately and properly (Solomon et al. (2004)). Parental disapprobation induces insecurity (associated with the prospect of parental abandonment). Hence, very early in life, children come to equate being good with being safe, and being bad with the anxiety of being insecure (Sullivan (1953)), which pushes them to perform well in order to gain love and protection. It is worth noting, however, that cultures often value different and sometime contradictory worldviews. With regard to the attitudes one should have towards money, cultural norms often encourage both generosity and accumulation of material wealth. The view that will prevail in case of an increase in mortality salience will depend on the norms which are salient in the situation (Jonas and Greenberg (2013)).

\section{Experimental Economics Literature on Status-Seeking}

A number of experimental studies have analyzed the role of status and social recognition on individual performance relying on a flat-wage scheme.

The work of Charness et al. (2013) particularly inspired our research. They studied whether individuals care about their status in a setting where status derives from receiving more or less salient information about their relative position in their group (i.e. public feedback). Relative position is determined by participants' performance in a real-effort task. One of the major results of their study is that individual performance is influenced by feedback on one's relative position in the group, as people tend to exert higher effort when they receive information about their rank publicly. The work of Kosfeld and Neckermann (2011) is also closely related. In a field experiment, they studied the impact of social recognition on students' performance and found that providing individuals with a congratulatory card for the best performance increased performance by about $12 \%$. Azmat and Iriberri (2010) exploited a natural experiment in a Spanish school where, for one year only, students were provided with relative performance feedback information (i.e., whether they were performing above or below their classmates' average) in addition to the usual individual performance information. They found that feedback information increased students' grade by about $5 \%$, and no discouraging effects on subjects with below-average performance.

For the purpose of our research, the major advantage of experimental investigations using

a flat-wage scheme is to disentangle the effect of monetary returns from that of performance comparisons. If individuals do not care about social recognition, theory predicts that any feed- 
back or purely symbolic awards will have zero effect on individuals' performance since effort is costly. But if individuals care about social recognition, as these studies indeed highlighted, a positive effort should be observed.

A number of experimental papers, which do not rely on flat-wage scheme, are also closely related to our research, as they provide individuals with feedback on their performance. Azmat and Iriberri (2011) studied the effect of the provision of informational feedback on agents' performance and emotional responses. They found that providing subjects with relative performance feedback boosted performance as well as feelings of dominance and happiness. In particular, they found a stronger effect under piece-rate incentives, whereas the effect under flat-rate incentives was milder. Similarly, Barankay (2011) and Eriksson et al. (2009) did not find any positive effect of providing participants with feedback rank information. On the other hand, Blanes i Vidal and Nossol (2011) found that when piece-rate incentives were used, providing individuals with relative performance feedback increased productivity. In these experiments, however, the information about individual rank always remained private.

In contrast with self-esteem, however, status seeking demands public recognition, and thus feedback information about relative performance must be common knowledge among the group of participants (see also Rustichini (2008), Charness et al. (2013)). For our research, therefore, the paper of Tran and Zeckhauser (2012) is illuminating as they distinguished between private and public feedback, and found that both had a positive effect on students' English tests score. This finding suggests that ranking can provide inherent incentive to perform, either to increase self-esteem or status.

Therefore, in the light of the above research, providing participants with feedback on their performance, we should observe a positive effort even though the economic incentives play in the opposite direction. To study self-esteem and status as "incentives", we elected to investigate the effect of both private and public feedback.

\section{The present research}

\subsection{Participants}

The experiment was run between April and May 2013 at the LES Laboratory of University of Bologna in Forlí Campus using z-Tree software (Fischbacher (2007)), and involved 126 students for a total of 9 sessions (i.e. about 30 students per treatment). The average payoff was about 8.5 Euro. Each session lasted for about one hour and did not start until all participants were familiar with the procedure. 


\subsection{Procedure}

We conducted the experiment for two environments, that is with Mortality Salience (MS) and with Music. As explained above, for each environment we considered two settings, with Private Feedback and with Public Feedback.

Writing an essay. In line with the TMT research, in the MS treatment we remind subjects of their own death before conducting the real-effort task. The standard procedure consists in two questions to be answered briefly asking participants to describe the emotions that the thought of their own death arouses in them and what would happen to them as they physically die. The exact questions to be answered are:

- "Please describe as specifically as you can the emotions that the thought of your own death arouses in you"

- "Please describe as specifically as you can what do you think will happen to you as you physically die"

In the Music treatment (i.e. our control sessions), subjects were asked to describe their feelings when listening to classical music. The exact questions to be answered are:

- "Please describe as specifically as you can the emotions that the thought of music arouses in you"

- "Please describe as specifically as you can what happen to you when you listen to classical music"

Immediately after writing the essay, participants rated, on a Likert scale ( $1=$ not much; $5=$ very much), the effort they put and the intensity of the emotion they felt in writing the essay. Finally, they reported whether they had experienced a loss in the recent past.

Incidental memory test. One crucial question for the present study is the success of the (death vs. music) priming strategy. Participants may or may not comply with the request of focusing on their own death, and, more in general, the priming strategy may be differentially effective at activating death-related or music-related thoughts across participants. We adopted several measures to assess the efficacy of our priming procedures. First of all, we evaluated whether the contents of the participants' reports were generally consistent with the task demands. They were: in all cases participants wrote about their own death in the MS treatments and about music in the Music treatments. Further, we devised an incidental memory task (Moscovitch and Talmi (2007)) to measure the relative accessibility of death (or music) contents after MS (or music) treatments. Immediately after writing about death (or music), participants were presented with pairs of words appearing on their computer screen. In each pair, one word was related to the main theme of the treatment - death for the MS treatments (e.g., " funeral"), 
music for the Music treatments (e.g., "violin") - whereas the other word was not related to the theme. Within 2 minutes, participants' task was to evaluate which of the two words was longer. In a later surprise memory test, ${ }^{4}$ participants were requested to recall as many words they could (i.e., an incidental memory test). The assumption is that those individuals for which the priming procedure was relatively more effective would be more inclined to attend to and successfully encode words congruent with the primed theme, resulting in increased recall rates for death related words (for the MS treatments) and music-related words (for the Music treatments) (e.g., Moores et al. (2003)). Subjects earned 0.25 cent for each word correctly recalled. Table (2) summarizes these variables, which will be used as control variables in our analyses (see below).

Personality questionnaire. Participants also filled out a personality questionnaire (i.e. a short version of the Big Five). The aim of completing such a questionnaire is twofold. First, about ten minutes need to elapse from the priming treatment to the real effort task as individuals' first reaction to conscious thoughts of mortality is to remove them from focal attention (see Arndt et al. (2004a)). Once these direct defenses against conscious thoughts of death are relaxed, death thought accessibility increases outside of conscious awareness. Second, personality traits - such as agreeableness and openness - may have an effect on our results via reciprocity toward the experimenter when a flat-wage is used (see, for example, Giannetti and Orsini (2014), Ben-Ner et al. (2004)). Even though subjects are provided with alternative activities (i.e. magazines), and are allowed to read their own materials, there is indeed the risk that subjects decide to perform the task because they felt obliged to do "something" once in the lab. We therefore used these personality traits as control variables in our regressions (see Section 5.21).

Real Effort Task. In all treatments, subjects performed a real-effort task (i.e., three-digits summations), which was paid a fixed amount of money (i.e. 7 Euro) regardless individual's performance (e.g. the number of correct answers). In this way, we rule out relative income feedback as a significant driver of performance (see, for example, Azmat and Iriberri (2010), Charness et al. (2013)). The task was not very difficult and a bit tedious in order to induce some disutility. In addition, subjects knew (as highlighted on the screen and reported in the instructions) they could stop at any time during the experiment. To allow for alternative activities we provided subjects with some magazines and we allowed them to read their own materials. Thereupon, the probability that subjects conducted the real-effort task simply to avoid boredom is substantially reduced (see also Charness et al. (2013)). However, no external aids (calculators, scratch paper, etc) were allowed.

In each of 7 periods, subjects were randomly allocated to groups of three participants. At the end of the period, we privately provided subjects with the number of correct answers and a ranking of the results in their group. More specifically, subjects were informed whether they

\footnotetext{
${ }^{4}$ The surprise consists of subjects being unaware that the memory test on the same group of words would have followed.
} 
ranked "First", "Second" or "Last" in their group (i.e. Private Feedback). We then repeated this exercise for seven periods. At the beginning of each period, we also privately provided each participant with their personal history in the entire game. To distinguish the effect of pure selfesteem from that of status-seeking, we run the same treatments making the personal history of individual ranking available to all participants in each peer group (i.e. subjects could see the entire history of their peers - Public Feedback). ${ }^{5}$ We thus have the $2 \times 2$ treatments as described in Table (1).

Exit questionnaire. To deal with possible confounders, we collected upfront through an exit questionnaire a series of information about subjects' attitudes and characteristics. As discussed above, an important concern that needs to be checked in our design is related to the use of flat-wage and individual attitude to reciprocate (see also Charness et al. (2013)). In addition to personality traits, we measured subjects' attitude to reciprocate relying on the following question "If someone does something that is beneficial for you, would you be prepared to return a favour even if this was not agreed upon in advance and may be costly for you"? from which we derive a general indicator of reciprocity.

We then collected additional participants' characteristics that turned out to be relevant in previous research on TMT. In particular, we collect information about participants' level of materialism, sex and age, because females have been often identified to dislike competition and to be less materialistic (see Rindfleisch et al. (2009), Croson and Gneezy (2009)), and sensitivity to the mortality salience may increase with age.

We also collected information on individual's level of uncertainty in relationships with others (i.e. Development Insecurity), in personal skills and abilities (i.e. Personal Insecurity), and in appearance and social interactions (i.e. Social Insecurity). As long as insecure subjects have weaker defense against the fear of death (see Rindfleisch et al. (2009)), the more insecure the subjects, the more likely the success of our priming strategy should be.

Finally, we needed to control for other possible cultural worldviews such as religion beliefs, which might have affected our priming strategy (Arndt et al. (2004b), Rindfleisch et al. (2009)). In particular, when subjects can rely on a greater number of cultural views, the priming strategy is likely to fail. We therefore asked our subjects to rate how much family, friends, work and religion were important in their life and included these variables as additional controls.

\subsection{Hypotheses}

According to TMT, our main hypothesis (H1) is that in the treatments with mortality salience individuals would feel more the psychological pressure to perform (under both private and public feedback on ranking) to increase their self-esteem. However, to the extent that sensitivity

\footnotetext{
${ }^{5}$ For an English translation of the Italian instructions, see Annex.
} 
to the flat-wage may increase as a result of the augmented materialism (see Kasser and Sheldon (2000), Arndt et al. (2004b))), participants'quest for self-esteem may be offset by the economic incentives to perform. We additionally hypothesized (H2) that the effect of MS induction would be reinforced when subjects are publicly informed about their ranking, as the drive of statusseeking is added to the drive of self-esteem.

\section{Experimental Results}

\subsection{Univariate Analysis}

In this section we present a comparative analysis of performance at session level across treatments. Figure (1) displays the distributions of the number of points across the two environments (with MS and with Music) and settings (with Private Feedback and Public Feedback). The number of points measures the number of correct summations entered by subjects in each period during the real effort task. At first sight, it is evident that the distributions of points for the treatments with mortality salience have a different shape in comparison to the distributions of points for the control treatment (i.e. music), both when private and public feedback are provided to the subjects. The result of public feedback per se is not so striking. ${ }^{6}$

To see whether these effects are statistically significant, we first compare across treatments (i.e. with MS and with Music) the mean values of the number of points computed by keeping for each session the average. The results (not reported) from these unpaired tests (TTEST) suggest there are no significant differences in the mean when comparing the distributions according to the priming strategy. There is instead a weak evidence (at 10\% level) for a difference in the mean of the distribution of points under the Public Feedback setting, which is higher than the mean of the distribution of points under the Private Feedback.

From these pictures, however, it is clear that comparing the means is not enough. Indeed the MANN-WITHNEY/Kolmogorov tests strongly reject in all cases the null hypothesis that groups are drawn from two populations with the same distribution. Overall, this analysis seems to suggest that our priming strategy has a strong effect on the variance of the distributions of points (i.e. lower variance in the treatment with mortality salience), whereas the effect of the public feedback is less clear.

For this reason, before proceeding to analyse the data at individual level, we investigate the effects of treatments on the variance of the effort among participants (see also Kosfeld and Neckermann (2011)). To this end we construct a Gini index to measure the inequality in the number of points in each period and session. ${ }^{7}$ The results are reported in Table (4). In col-

\footnotetext{
${ }^{6}$ These pictures have been drawn including under the mortality treatments also those subjects who experienced a loss in the recent past. The distributions without controlling for loss experience are substantially similar.

${ }^{7}$ The Gini coefficient is generally used as a measure of inequality of income distribution. It is defined as a ratio
} 
umn $a$ we start by adding a dummy variable for mortality treatments and public feedback. The coefficient for the mortality treatments is negative and statistically significant suggesting that the variance of the distributions is significantly lower when subjects are reminded of their own death (i.e. a low Gini coefficient indicates a more equal distribution). The coefficient on public feedback instead is not statistically significant. In column $b$ we add an interaction term between these two variables. The public feedback dummy is now statistically significant, whereas the additional effect under the mortality treatment (i.e the interactions term) is positive and significant. This latter effect, however, is not statistically significant from column $c$ to $e$ when we add few controls computed at session level (i.e. the average in each session). More specifically, in column $c$ we add the share of subjects in each session who experienced the loss of a beloved, in column $d$ we add the subjects' average ability in mathematics, while in column $e$ we include the share of female along with subjects' average age (see Table (3) for a description of these variables). These variables are not significant, and allow us to conclude that both public feedback under the Music treatment and Mortality salience under the private treatment decrease the variability of the distributions of points. That is, our participants tend to behave more similarly under these treatments. We can also observe that there is no additional effect when providing public feedback under the mortality treatment.

\subsection{Multivariate Analysis: individual performance}

In this section we analyse the subjects' (absolute) performance under different treatments, while accounting for a number of control variables measured at the individual level. As the dependent variable will be the absolute number of points in each period which is left-censored at zero, we rely on a Tobit model which is suited for this type of variable.

As highlighted above, in our experiment it is crucial to control for the success of the priming strategy. This is confirmed by the empirical analysis of the determinants of the total number of correct answers. In Table (5), column $a$, the coefficient on the dummy for the MS treatment is negative and statistically significant suggesting that subjects under the mortality treatment entered a lower number of summations. However, when we add in column $b$, the number of words a subject was able to remember from the incidental memory task in the mortality treatments and in the music control treatments (Words Recall Mortality and Words Recall Music), the coefficient on the treatment dummy remains negative and statistically significant, whereas the coefficient on Word Recall Mortality itself is positive and significant, suggesting that individuals for which the priming strategy was more effective tended to insert a larger number of summations. In contrast, the coefficient on World Recall Music is not statistically significant. Notably,

with values between 0 and 1 , where 0 corresponds to perfect equality (everyone having exactly the same income) and 1 corresponds to perfect inequality (where only one person has all the income). Thus, a low Gini coefficient indicates more equal distribution, while a high Gini coefficient indicates more unequal distribution. 
this results holds if we replace the Words Recall Mortality and Words Recall Music with the relative frequency of treatment (death or music) - related words and neutral (non theme-related) words a subject was able to remember out of the total number of studied words (see again Table (2)). This result indicates that it was only the propensity to retrieve death related words in the MS condition (and hence the relative strength of the MS induction), and not the mere quantity of words recalled, that had an impact of performance in the real-effort task. This finding discourages to think that a common underlying factor drove subjects to recall more words and enter more summations, consistent with the evidence that the number of words in the Music condition had no effect on performance. We, however, prefer to keep the Words Recall Mortality and World Recall Music variables as in this way are easier to read: we can interpret the coefficient as the effect arising for one additional word the subject is able to remember.

At first sight, this result seems to highlight two types of opposite behaviour among the group of subjects primed with death-related thoughts. ${ }^{8}$ As a further check, in column $c$ we add subjects past ability in mathematics (Math Ability), ${ }^{9}$ along with a dummy variable equal to 1 for those subjects who experienced the loss of a beloved in the recent past (Loss). Although the coefficient on Math Ability has a positive and significant effect on the number of entered summations, the size and significance on Words Recall Mortality have not changed. The additional control for mortality salience - Loss - does not turn out to be significant.

In column $d$ we add a categorical variable (Period), which accounts for possible trends in the experiment. This variable turns out to be positive and significant, meaning that subjects progressively entered a greater number of summations, suggesting either there was a learning effect or subjects became more competitive. It is interesting to note that this effect tends to disappear when subjects are provided with public feedback, while it tends to persist in the treatments with mortality salience (see the interaction terms in column $e$ ). Therefore, as it will be confirmed further below, (a group of) subjects tend to become more competitive under the mortality treatment as the time goes by.

\subsubsection{Robustness checks}

In Table (6), we controlled for the robustness of the previous results to a number of controls. First, we rely on a general indicator of reciprocity. The inclusion of this variable in column $a$ does not alter our results. Second, we control for individual agreeableness and openness (as

\footnotetext{
${ }^{8}$ These two types of behaviour ruled also out the possibility of ego-depletion of our subjects in the MS treatments. If there are individuals who still manage to keep their performance up to and above the average, the main driver of low-performance is not the draining of mental resources.Thus, our results suggest that writing on deathrelated thoughts is demanding as much as writing about music, consistent with the absence of difference in ratings of effort conditions (see Table (2)).

${ }^{9}$ Individual math ability has been measured by asking subjects to rate - from one (i.e. definitely no) to five (i.e. definitely yes) - their agreement with the following statement: "In the past I have proved to have good mathematical skills".
} 
measured through the short version of the big-five questionnaire). When we add in column $b$ these alternative proxies for reciprocity (Agreeableness and Openness) our results do not change. We thus conclude that reciprocity toward the experimenter is not playing any role (see also Giannetti and Orsini (2014)).

In column $c$ we add two indicators on the effectiveness of our priming strategy (see again Table (2)), which respectively account for the effort subjects exerted (i.e. Priming Effort), and the emotions they proved (i.e. Priming Emotion), while writing their essay. Also in this case the results are the same.

In column $d$ we add participants' age (i.e. Age) and sex (i.e. Female), while in column $e$ we add controls on individual's level of uncertainty in relationships with others (i.e. Development Insecurity), in personal skills and abilities (i.e. Personal Insecurity), and in appearance and social interactions (i.e. Social Insecurity). Although Personal Insecurity is slightly significant at $10 \%$ level, the size and significance of the coefficients on the main variables of our interest do not change. Finally, we also controlled for other possible cultural worldviews such as religion beliefs, family, friends, work attachment. The results (not reported) are robust to these last controls as well.

\subsection{Dynamics in performance and ranking}

In the previous section, we have studied the absolute number of correct answers. We now aim to analyze the first difference (i.e. the difference between two adjacent periods) in the number of correct answers and in subjects' ranking positions to see whether there is any effect of our

priming strategy on the dynamics of performance and a change in the behaviour during the experiment (see Charness et al. (2013) for a similar analysis).

We begin Table (7) by studying the first difference in the number of points. In column $a$, in addition to the usual variables accounting for the various treatments, we add a dummy variable which is equal to 1 if the subject ranked first in the previous period (i.e. Ranked 1st (t-1)), and a dummy variable which is equal to 1 if the subject ranked second in the previous period (i.e. Ranked 2nd ( $\mathrm{t}-1)$ ). The base category comprises subjects who ranked 3rd in the previous period (i.e. Ranked 3rd ( $t-1)$ ). The results indicate there is no treatment effects: the dummy variable on mortality salience is not statistically significant. Instead, the dummy variable on public feedback is negative and statistically significant suggesting that under this setting individuals tend to decrease their performance over period with respect to the private music treatment (i.e. the base category). The dummy variables on rank positions are both negative and statistically significant, suggesting that the variation in the number of points between two periods is negative for individuals who ranked first or second in the previous period. These subjects tend thus to reduce their performance in the following period. From column $b$ to $e$, we continue to add our controls for the priming strategy and individual ability. Interesting to note, 
only the variable measuring the number of words an individual was able to remember in the mortality salience treatments is again positive and slightly significant, whereas mathematical ability is not significant. These results further suggest that individuals who more successfully attended death-related items tend to improve their performance during the task in the quest for self-esteem. We have also tried to interact the variables on past rank with the dummy variables for mortality salience and public feedback. No significant results, however, emerged.

In Table (8) we again study the dynamics between treatments, but this time focusing on firstdifference in ranking rather than on the first-difference in the number of correct answers as in Table (7). In column $a$ we see there is no effect arising from the mortality salience and public feedback. The dummy variables on rank positions are negative and statistically significant, this time suggesting that the difference in ranking positions between two periods is negative (i.e. improve) for individuals who ranked in the top positions in the previous period. In general, individuals thus tend to maintain or improve their rank in the following period (i.e. "success breads success"). Along with the previous one on the absolute number of points, this result suggests that these individuals tend to reduce their effort but in a way that still allows them to be among the best performers.

From column $b$ to $d$ we add the usual controls. Once again, the coefficient of the variable accounting for the words subjects were able to remember under the mortality treatment is negative and significant, whereas math ability is not statistically significant. These results further suggest that those individuals for which the priming strategy was more effective tend to rank better in the experiment. However, the interaction between ranking positions and the dummy accounting for mortality salience is now statistically significant indicating that when subjects are primed with death-related thoughts, they tend on average - with respect to the private music treatment (i.e. now the base category) - to worsen their position if in the previous period they were among the best performers. Thus, in the mortality treatment, the reduction of the variance in the number of points we observe in Figure (1) can be attributed to those subjects that tend to reduce their effort once they have gained self-esteem, as well as to those subjects who ranked low and tend to increase their effort. Hence, for this group of subjects the main driver after the mortality salience seems to be the economic incentive to not perform, which tends to overtake the quest for self-esteem, thus resulting in conformism. In other words, at least initially these subjects exposed to death related thoughts tend to exert more effort in the task, in the quest for self esteem and status. However, they have not a clear belief/expectation on the due amount of effort which is required to get ahead in the group rank. As the task goes on and more feedback on their relative performance are available, they adjust their effort to get a decent position without incurring in too much disutility, thus paying more care to the economic incentives to not perform. This process is reasonable and as such it might be at work in any treatment, but we find it statistically relevant only for this group of subjects in the MS treatments. 
We also tried to interact previous rank positions with the Words Recall Mortality (not reported) to see whether this effect is playing a role also for the smaller group of subjects who recall a higher number of words in the incidental memory test. No significant results emerged. We thus conclude that for this group of subjects the main driver of their behaviour is the constant quest for self-esteem.

In support of this interpretation, we finally split our sample in relation to subjects' level of materialism (results are available upon request). More specifically, we split our sample in two groups: below and above the mean level of an indicator of materialism (collected through the exit questionnaire, see also Rindfleisch et al. (2009)). The distribution of this indicator is negatively skewed (i.e. the mean is below the median) so the second group of subjects is larger than the first group. Consistent with the above discussion, we find that the dummy variable for the $M S$ treatments is negative and statistically significant for more materialistic subjects (i.e. the larger group) whereas the effect of Words Recall Mortality is not statistically significant. The opposite is true for the smaller group of less materialistic subjects.

To sum up, our conclusion is that the MS priming makes most subjects more sensitive to in-group conformity: they do not want to be the last in the rank, but they do not want to be the only members of the group who spend effort either. There is a double target to be hit: not to perform too poorly (i.e.thus enhancing self-esteem), and not to work more than needed (as it is not paid). Subjects treated with MS are more sensitive to these two targets, and their behaviour tend to be thus more conformist. However, a smaller group of less materialistic subjects entirely disregard the economic incentive to not perform in the task and constantly keep a high level of performance in the quest for self-esteem.

\subsection{Discussion}

Our results suggest that, when mortality salience increases, individuals generally tend to perform more homogeneously, conforming to other's behavior. This result is in line with previous psychological research on mortality salience (see, for example, Kasser and Sheldon (2000), Arndt et al. (2004b)), showing that individuals tend to become more materialistic (i.e. more sensitive to economic incentives) and less creative (i.e. to reduce differentiation from the majority position) after thinking about death. We also found that when subjects have been reminded of their own death, no additional effect was observed from the provision of a public feedback in addition to a private one, as if self-esteem - rather than status-seeking - was the main driver of individual behaviour after MS induction.

One objection to our experimental design might be that individuals exert effort simply to please the experimenter perceived as an authority (Zizzo (2010)) or to behave nicely towards him/her (Giannetti and Orsini (2014)). We believe, however, that these effects are not playing a crucial role in explaining our results. First of all, we avoid having our students in the lab. 
Second, at the end of the experiment we ask students their opinion about the objectives of our experiment. From the answers they gave, we can be confident they were really unaware of the experimental hypotheses. Finally, as explained above (see Section 5.2.1), we collected and included in our regressions a large number of controls that have been proved to be associated with nice and reciprocating behaviour (Ben-Ner et al. (2004); Giannetti and Orsini (2014)).

We also check for different specifications of our model. In particular, we check for any selection effect by running a series of Heckman-selection models to see whether there were significant differences between subjects who decided to exert a positive effort and subjects who decided to stay out of the competition at all. No selection effects have emerged and results are substantially identical.

We are thus confident that our experimental design was able to isolate the effect of mortality salience on individual self-esteem and status-seeking when the economic incentives direct subjects to provide zero effort.

\section{Conclusions}

Humans are the only living beings aware of their own mortality. As postulated by the Terror Management Theory (TMT), a large proportion of human behaviour is motivated by the need to defend oneself from the existential anxiety that arises from this mortality awareness. By investing in cultural worldviews that provide meanings, individuals obtain protection and an anxiety buffer. The mechanism at work is individual self-esteem: as long as individuals believe they are meeting the standard of value prescribed by the worldview, individuals feel "valuable contributor to a meaningful universe".

The aim of this experiment was to combine insights for the TMT in an economic experiment with incentive-compatible mechanism to disentangle the effects of an increased mortality salience on individual performance via self-esteem and status-seeking. After writing about death or a control topic (i.e. music), subjects were thus randomly matched in groups of three to perform a real-effort task (i.e. three-digits summations), for which they got a fixed wage. As status seeking requires some form of public recognition, they were then provided either with private or public feedback on their relative position.

Our results suggest that, under mortality salience, individuals initially tend to exert more effort to rank higher to gain in self-esteem; as time goes by, however, individuals who got the best positions tend to reduce their performance to reduce economic disutility (as they are paid a fixed wage regardless of performance). However, in a subset of participants, for which the MS induction was most effective (as reflected in a higher proportion of death-related words recalled), we do not observe such a reduction in performance (and rank positions) in time, as if the need to maintain self-esteem was the main driver of their behaviour. These individuals 
turned out to be the least materialistic of the sample. On the contrary, for another subset of more materialistic subject (i.e. for which the economic incentives are stronger), we do observe a sharp reduction in performance with time. As a result of these two specular tendencies, the distributions of points under the mortality salience exhibited a lower variance than that in the control treatments.

As anticipated, the effect of public feedback per se does not have any additional effect once subjects have been reminded of their own death, as if intrinsic motivation of individuals and not individuals' need for public recognition drove subjects' behaviour.

Our results are generally in line with previous research on mortality salience (see, for example, Kasser and Sheldon (2000); Arndt et al. (2004a)) showing that, when reminded of their own death, individuals tend to become more materialistic and minimize the level of their differentiation from others. A closer inspection of the data, however, helps qualifying John Donne's famous saying "death makes us all equal when it comes": This is favoured by materialism, and counteracted by vivid experience of death-related contents. 


\section{References}

Arndt, J., Cook, A., Routledge, C., 2004a. The blueprint of terror management. Handbook of experimental existential psychology, 37.

Arndt, J., Solomon, S., Kasser, T., Sheldon, K. M., 2004b. The urge to splurge: A terror management account of materialism and consumer behavior. Journal of Consumer Psychology 14 (3), 198-212.

Azmat, G., Iriberri, N., 2010. The importance of relative performance feedback information: Evidence from a natural experiment using high school students. Journal of Public Economics $94(7), 435-452$.

Azmat, G., Iriberri, N., 2011. The provision of relative performance feedback information: An experimental analysis of performance and happiness. Universitat Pompeu Fabra Working Paper.

Barankay, I., 2011. Rankings and social tournaments: Evidence from a crowd-sourcing experiment. Tech. rep., Working Paper.

Becker, E., 2007. The denial of death. Free Press.

Ben-Ner, A., Putterman, L., Kong, F., Magan, D., 2004. Reciprocity in a two-part dictator game. Journal of Economic Behavior \& Organization 53 (3), 333-352.

Blanes i Vidal, J., Nossol, M., 2011. Tournaments without prizes: evidence from personnel records. Management science 57 (10), 1721-1736.

Charness, G., Masclet, D., Villeval, M. C., 2013. The dark side of competition for status. Management Science 60 (1), 38-55.

Croson, R., Gneezy, U., 2009. Gender differences in preferences. Journal of Economic Literature 47 (2), 448-74.

Eriksson, T., Poulsen, A., Villeval, M. C., 2009. Feedback and incentives: Experimental evidence. Labour Economics 16 (6), 679-688.

Fischbacher, U., June 2007. z-tree: Zurich toolbox for ready-made economic experiments. Experimental Economics 10 (2), 171-178.

Giannetti, C., Orsini, R., 2014. Being nice with the experimenter? Applied Economics Letters $21(12), 857-861$. 
Greenberg, J., Solomon, S., Pyszczynski, T., 1997. Terror management theory of self-esteem and cultural worldviews: Empirical assessments and conceptual refinements. Advances in experimental social psychology 29, 61-139.

Jonas, E., Greenberg, J., 2013. Generosity, greed, norms, and death-differential effects of mortality salience on charitable behavior. Journal of Economic Psychology.

Kasser, T., Sheldon, K. M., 2000. Of wealth and death: Materialism, mortality salience, and consumption behavior. Psychological Science 11 (4), 348-351.

Kosfeld, M., Neckermann, S., 2011. Getting more work for nothing? symbolic awards and worker performance. American Economic Journal: Microeconomics 3 (3), 86-99.

Moores, E., Laiti, L., Chelazzi, L., 2003. Associative knowledge controls deployment of visual selective attention. Nature neuroscience 6 (2), 182-189.

Moscovitch, M., C. J., Talmi, D., 2007. Learning, memory, \& knowledge. In: (Ed.), B. B. (Ed.), Cognition, Brain, and Consciousness. Elsevier Science, Amsterdam, pp. 397-405.

Rindfleisch, A., Burroughs, J. E., Wong, N., 2009. The safety of objects: Materialism, existential insecurity, and brand connection. Journal of Consumer Research 36 (1), 1-16.

Rustichini, A., 2008. Dominance and competition. Journal of the European Economic Association $6(2-3), 647-656$.

Simon, L., Greenberg, J., Harmon-Jones, E., Solomon, S., Pyszczynski, T., Arndt, J., Abend, T., et al., 1997. Terror management and cognitive-experiential self-theory: Evidence that terror management occurs in the experiential system. Journal of personality and social psychology $72,1132-1146$.

Solomon, S., Greenberg, J., Pyszczynski, T., 2004. The cultural animal: Twenty years of terror management theory and research.

Sullivan, H. S., 1953. The interpersonal theory of psychiatry.

Tran, A., Zeckhauser, R., 2012. Rank as an inherent incentive: Evidence from a field experiment. Journal f Public Economics 96 (9-10), 645 -650.

Zizzo, D. J., 2010. Experimenter demand effects in economic experiments. Experimental Economics 13 (1), 75-98. 
Table 1: Mortality SAliEnCE (MS): Experimental Hypotheses

\begin{tabular}{|c|c|c|}
\hline \multicolumn{2}{|c|}{ TREATMENT } & Music \& Public Feedback \\
\hline \hline Music \& Private Feedback & $\begin{array}{c}\text { H2: stat. sign. (due to } \\
\text { status seeking) }\end{array}$ \\
\hline MS \& Private Feedback & MS \& Public Feedback & $\begin{array}{c}\text { H2: stat. sign (due to } \\
\text { status seeking) }\end{array}$ \\
\hline H1: stat. sign. due to MS & H1: stat. sign. due to MS & \\
\hline
\end{tabular}

Table 2: PRIMING STRATEGY SUCCESS

The variable Total words measures the total number of words, while Non-theme related words measures the total number of neutral words, subjects were able to recall in the incidental memory test. The variable Treatment words measures the number of death-related words and the number of music-related words subjects were able to remember in the MS and Music treatment respectively. Loss experience represents the share of subjects who experienced a mourning of a beloved in the recent past. Effort is a self-reported indicator which measures the effort subjects put in writing the essay, whereas Emotion measures in a similar way the emotion they prove while writing it.

\begin{tabular}{|l|c|c|c|c|c|c|c|c|c|c|c|}
\hline & \multicolumn{4}{|c|}{ MORTALITY } & \multicolumn{4}{c|}{ MUSIC } & DIFF \\
\cline { 1 - 9 } & Mean & Std & Min & Max & N & Mean & Std & Min & Max & N & MS vS MUIC \\
\hline \hline Total words & 6.367 & 4.002 & 0 & 14 & 66 & 4.033 & 3.124 & 0 & 10 & 60 & $\mathrm{p}<0.01$ \\
\hline Non-theme related words & 1.758 & 0.174 & 0 & 5 & 66 & 1.350 & 0.172 & 0 & 5 & 60 & $\mathrm{p}<0.05$ \\
\hline Treatment words (abs) & 4.606 & 2.997 & 0 & 11 & 66 & 2.683 & 2.340 & 0 & 7 & 60 & $\mathrm{p}<0.05$ \\
\hline Loss experience & 0.272 & 0.449 & 0 & 1 & 66 & 0.200 & 0.403 & 0 & 1 & 60 & $\mathrm{p}=0.171$ \\
\hline Effort & 3.433 & 0.871 & 1 & 5 & 66 & 3.379 & 0.696 & 2 & 5 & 60 & $\mathrm{p}=0.349$ \\
\hline Emotion & 2.413 & 0.993 & 1 & 5 & 66 & 3.300 & 1.124 & 1 & 5 & 60 & $\mathrm{p}=0.380$ \\
\hline
\end{tabular}


Figure 1: Distributions of Performance (Points) ACross Treatments
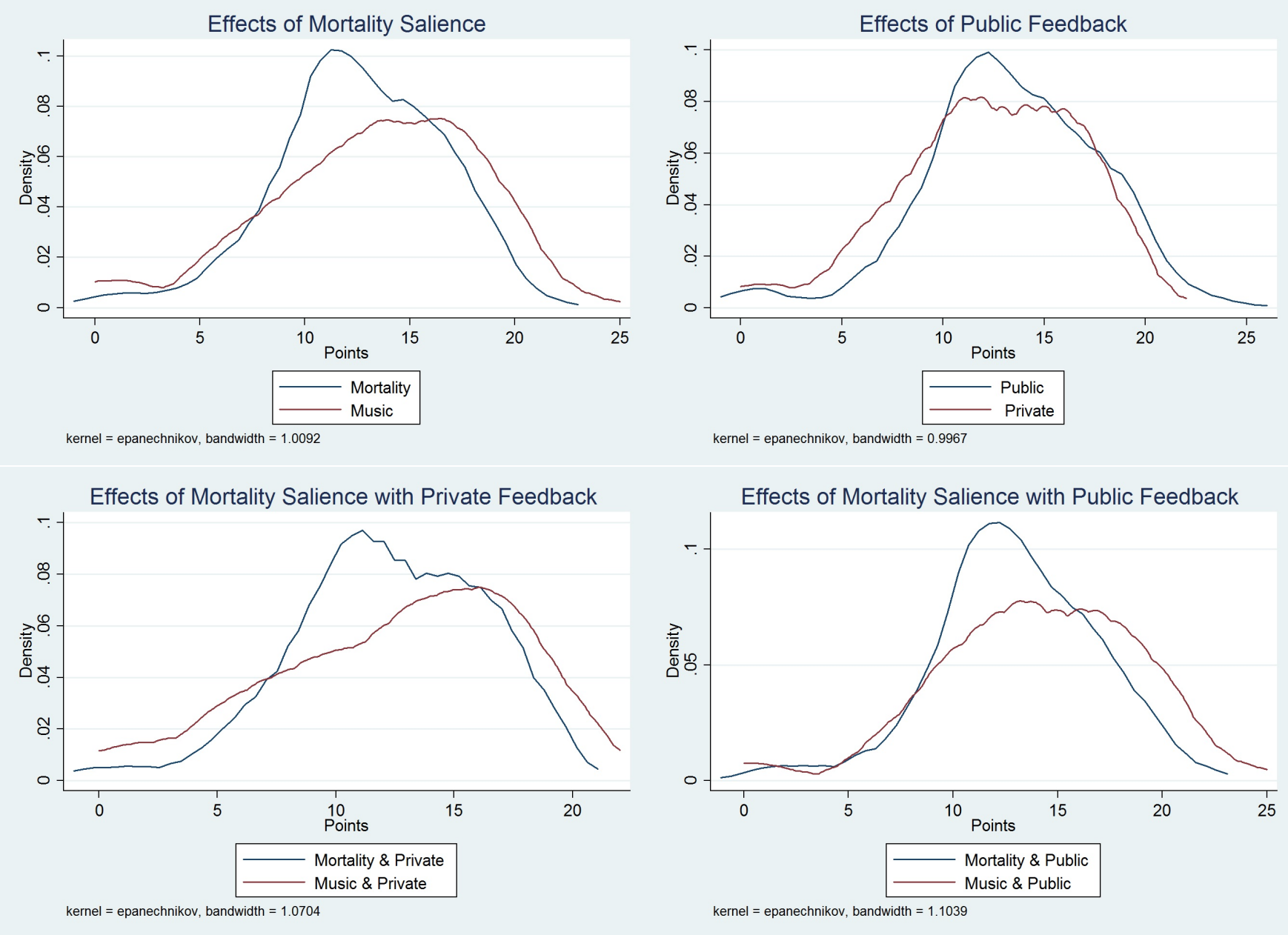


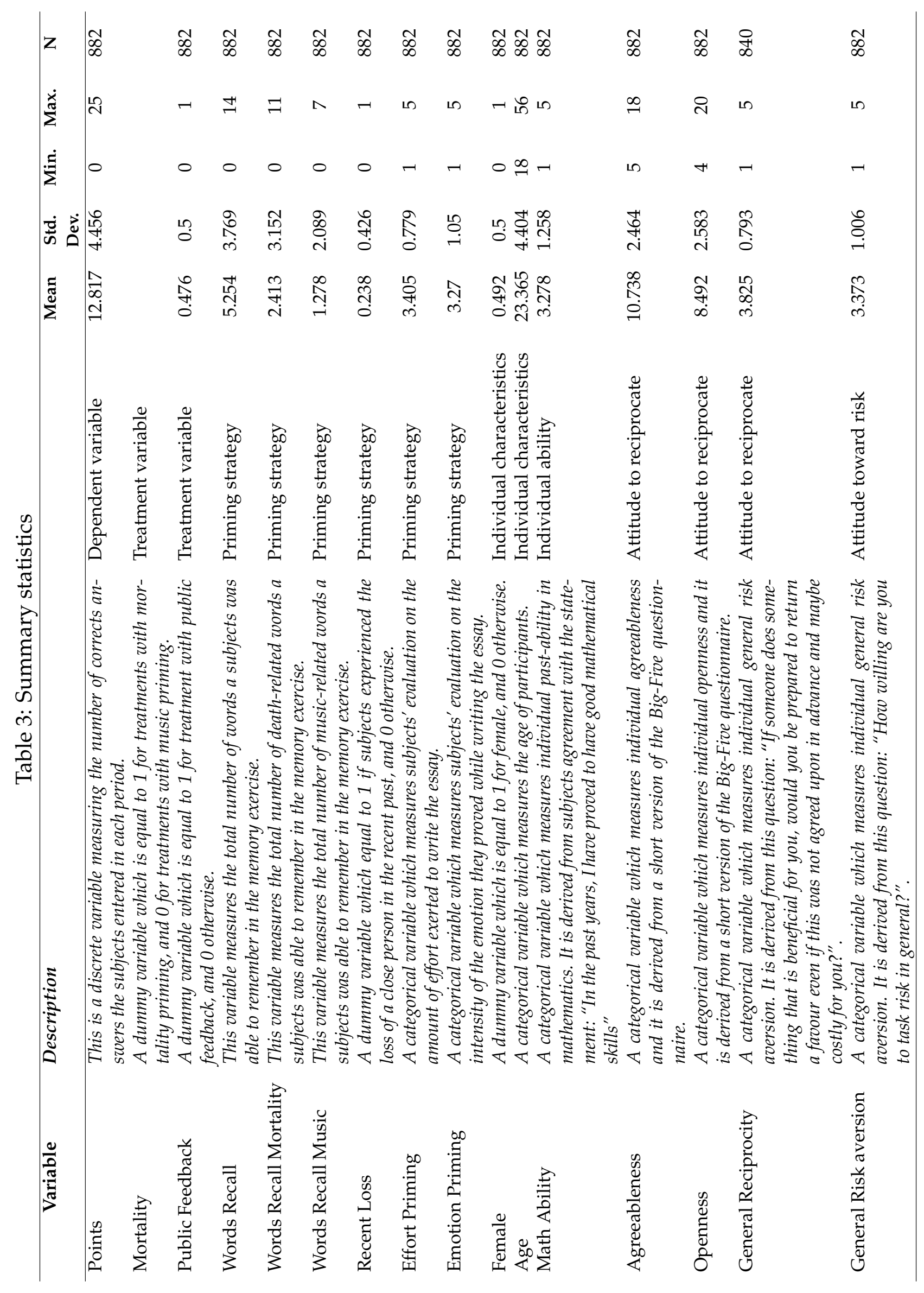


Table 4: Performance inequality (Session Gini Index) across Treatments

The dependent variable is the Gini index of the point distribution computed at session level for each period (i.e. 9 sessions for 7 periods). Mortality is a dummy variable equal to 1 for sessions with mortality salience and 0 otherwise, whereas Public Feedback is equal to 1 for sessions with public feedback and 0 otherwise. Average Loss is the share of participants in each session that experienced a loss in the recent past (i.e. the session average of Loss), Average Math Ability is the average subjects' ability in mathematics in each session (i.e. the session average of Math Ability), Average Age is the average subjects' age in each session, and Average Female is the share of female participants in each session (i.e. the session average of Female). See Table (3)).

\begin{tabular}{lccccc}
\hline & $a$ & $b$ & $c$ & $d$ & $e$ \\
\hline Mortality & $-0.0360^{* * *}$ & $-0.0565^{* * *}$ & $-0.0589^{* * *}$ & $-0.0491^{* * *}$ & $-0.0477^{*}$ \\
& $(0.009)$ & $(0.012)$ & $(0.013)$ & $(0.013)$ & $(0.028)$ \\
Public Feedback & -0.0070 & $-0.0315^{* *}$ & $-0.0315^{* *}$ & $-0.0315^{* *}$ & $-0.0381^{* *}$ \\
& $(0.009)$ & $(0.013)$ & $(0.013)$ & $(0.013)$ & $(0.017)$ \\
Public Feedback${ }^{*}$ Mortality & & $0.0450^{* *}$ & $0.0619^{*}$ & 0.0544 & 0.0582 \\
& & $(0.018)$ & $(0.034)$ & $(0.033)$ & $(0.036)$ \\
Average Loss & & & -0.0726 & -0.0651 & 0.0560 \\
& & & $(0.124)$ & $(0.119)$ & $(0.181)$ \\
Average Math Ability & & & & $0.0373^{* *}$ & 0.0157 \\
& & & & $(0.015)$ & $(0.039)$ \\
Average Age & & & & & -0.0141 \\
& & & & & $(0.016)$ \\
Average Female & & & & & 0.0214 \\
& & & & $0.149)$ \\
Constant & $0.1761^{* * *}$ & $0.1883^{* * *}$ & $0.2029^{* * *}$ & 0.0771 & 0.4389 \\
& $(0.008)$ & $(0.009)$ & $(0.027)$ & $(0.056)$ & $(0.471)$ \\
\hline Observations & 63 & 63 & 63 & 63 & 63 \\
\hline \hline
\end{tabular}

${ }^{*} \mathrm{p}<0.10,{ }^{* *} \mathrm{p}<0.05,{ }^{* * *} \mathrm{p}<0.01$ 
Table 5: INDIVIDUAL PERFORMANCE (POINTS) ACROSS TREATMENTS: TOBIT REGRESSION The dependent variable is the number of points individuals obtained in each period. Mortality treatment is a dummy variable equal to 1 if subjects were primed with death-related thoughts, whereas it is equal to 0 if subjects were primed with music thoughts. Public feedback is a dummy variable equal to 1 if subjects received a public feedback on individual rank, whereas it is equal to 0 if subjects received a private feedback. Words recall mortality is equal to the total number of death-related words subjects were able to remember during the incidental memory test in the mortality treatments, while Words recall music is the total number of music-related words subjects were able to remember in the music treatments. Loss is equal to 1 if subjects experienced a loss in the recent past and 0 otherwise. Math ability is a categorical variable which captures individuals ability in math as reported by the subjects in the exit questionnaire. Period is a categorical variable, which ranges from 1 to 7 and account for the period of the game. For a more detailed description, see Table (3).

\begin{tabular}{|c|c|c|c|c|c|}
\hline & $a$ & $b$ & $C$ & $d$ & $\mathrm{e}$ \\
\hline \multirow[t]{2}{*}{ Mortality Treatment } & -2.529 & $-5.039 * *$ & $-4.602^{* *}$ & $-4.601^{* *}$ & $-4.636^{* *}$ \\
\hline & $(1.869)$ & $(2.064)$ & $(2.027)$ & $(2.026)$ & $(2.051)$ \\
\hline \multirow[t]{2}{*}{ Public Feedback } & 1.381 & 1.192 & 1.302 & 1.303 & $2.394^{*}$ \\
\hline & $(1.414)$ & $(1.399)$ & $(1.368)$ & $(1.367)$ & $(1.402)$ \\
\hline \multirow{2}{*}{ Public Feedback*Mortality } & 1.148 & 1.823 & 1.517 & 1.516 & 1.514 \\
\hline & $(2.342)$ & $(2.285)$ & $(2.247)$ & $(2.246)$ & $(2.247)$ \\
\hline \multirow[t]{2}{*}{ Words Recall Mortality } & & $0.471^{* * *}$ & $0.461^{* * *}$ & $0.461^{* * *}$ & $0.461^{* * *}$ \\
\hline & & $(0.157)$ & $(0.153)$ & $(0.153)$ & $(0.153)$ \\
\hline \multirow[t]{2}{*}{ Words Recall Music } & & 0.123 & 0.081 & 0.081 & 0.081 \\
\hline & & $(0.215)$ & $(0.212)$ & $(0.211)$ & $(0.212)$ \\
\hline \multirow[t]{2}{*}{ Loss } & & & -0.337 & -0.338 & -0.337 \\
\hline & & & $(0.791)$ & $(0.791)$ & $(0.791)$ \\
\hline \multirow[t]{2}{*}{ Math Ability } & & & $0.611^{* *}$ & $0.611^{* *}$ & $0.611^{* *}$ \\
\hline & & & $(0.264)$ & $(0.264)$ & $(0.264)$ \\
\hline \multirow[t]{2}{*}{ Period } & & & & $0.234^{* * *}$ & $0.360^{* * *}$ \\
\hline & & & & $(0.039)$ & $(0.069)$ \\
\hline \multirow[t]{2}{*}{ Period*Public Feedback } & & & & & $-0.272^{* * *}$ \\
\hline & & & & & $(0.078)$ \\
\hline \multirow[t]{2}{*}{ Period ${ }^{*}$ Mortality } & & & & & 0.009 \\
\hline & & & & & $(0.078)$ \\
\hline Session Dummies & Yes & Yes & Yes & Yes & Yes \\
\hline 11 & -2175 & -2170 & -2168 & -2150 & -2144 \\
\hline $\mathrm{N}$ & 882 & 882 & 882 & 882 & 882 \\
\hline
\end{tabular}

${ }^{*} \mathrm{p}<0.10,{ }^{* *} \mathrm{p}<0.05,{ }^{* * *} \mathrm{p}<0.01$ 
Table 6: ESTIMATION RESULTS INDIVIDUAL PERFORMANCE (POINTS): TOBIT REGRESSION WITH INDIVIDUAL CONTROLS

The dependent variable is the number of points individuals obtained in each period. Mortality Treatment, Public Feedback, Words Recall Mortality, Words Recall Music, Loss, Math Ability, and Period are defined in the same way as in Table (5). Reciprocity is a categorical variable which captures individuals' attitude to reciprocate. Effort Priming and Emotion Priming are categorical variables (from 1 to 5) which measures subjects level of effort and emotion while writing their essay. Agreeableness and Openness are the corresponding behavioural traits as measured through an entry questionnaire. Age is a variable which measures individual age, whereas Female is a dummy variable equal to 1 for female participants, and 0 otherwise. Social, Personal and Development insecurity are categorical variables controlling for individual insecurity. For a more detailed description, see Section 4.3.1 and Table (3).

\begin{tabular}{|c|c|c|c|c|c|}
\hline & $\mathrm{a}$ & $\mathrm{b}$ & C & $\mathrm{d}$ & $\mathrm{e}$ \\
\hline Mortality Treatment & $\begin{array}{l}-1.361 \\
(1.558)\end{array}$ & $\begin{array}{l}-3.754^{*} \\
(2.065)\end{array}$ & $\begin{array}{c}-4.604^{* *} \\
(2.017)\end{array}$ & $\begin{array}{l}-3.407 \\
(2.077)\end{array}$ & $\begin{array}{c}-4.038^{* *} \\
(2.054)\end{array}$ \\
\hline Public Feedback & $\begin{array}{c}2.230 \\
(1.432)\end{array}$ & $\begin{array}{c}2.165 \\
(1.392)\end{array}$ & $\begin{array}{c}1.915 \\
(1.429)\end{array}$ & $\begin{array}{c}2.112 \\
(1.395)\end{array}$ & $\begin{array}{l}2.530^{*} \\
(1.399)\end{array}$ \\
\hline Public Feedback ${ }^{*}$ Mortality & $\begin{array}{l}-1.729 \\
(1.979)\end{array}$ & $\begin{array}{c}1.768 \\
(2.224)\end{array}$ & $\begin{array}{c}1.559 \\
(2.230)\end{array}$ & $\begin{array}{c}1.931 \\
(2.237)\end{array}$ & $\begin{array}{l}1.709 \\
(2.235)\end{array}$ \\
\hline Words Recall Mortality & $\begin{array}{l}0.453^{* * *} \\
(0.161)\end{array}$ & $\begin{array}{l}0.436^{* * *} \\
(0.153)\end{array}$ & $\begin{array}{l}0.452^{* * *} \\
(0.153)\end{array}$ & $\begin{array}{l}0.392^{* *} \\
(0.157)\end{array}$ & $\begin{array}{l}0.415^{* * *} \\
(0.152)\end{array}$ \\
\hline Words Recall Music & $\begin{array}{c}0.070 \\
(0.218)\end{array}$ & $\begin{array}{c}0.182 \\
(0.217)\end{array}$ & $\begin{array}{c}0.083 \\
(0.212)\end{array}$ & $\begin{array}{c}0.167 \\
(0.219)\end{array}$ & $\begin{array}{c}0.170 \\
(0.214)\end{array}$ \\
\hline Loss & $\begin{array}{l}-0.380 \\
(0.826)\end{array}$ & $\begin{array}{l}-0.390 \\
(0.783)\end{array}$ & $\begin{array}{l}-0.610 \\
(0.806)\end{array}$ & $\begin{array}{l}-0.521 \\
(0.789)\end{array}$ & $\begin{array}{l}-0.359 \\
(0.783)\end{array}$ \\
\hline Math Ability & $\begin{array}{l}0.635^{* *} \\
(0.277)\end{array}$ & $\begin{array}{l}0.639^{* *} \\
(0.261)\end{array}$ & $\begin{array}{l}0.604^{* *} \\
(0.262)\end{array}$ & $\begin{array}{l}0.627^{* *} \\
(0.261)\end{array}$ & $\begin{array}{l}0.507^{*} \\
(0.275)\end{array}$ \\
\hline Period & $\begin{array}{l}0.322^{* * *} \\
(0.056)\end{array}$ & $\begin{array}{l}0.365^{* * *} \\
(0.054)\end{array}$ & $\begin{array}{l}0.365^{* * *} \\
(0.054)\end{array}$ & $\begin{array}{l}0.365^{* * *} \\
(0.054)\end{array}$ & $\begin{array}{l}0.365^{* * *} \\
(0.054)\end{array}$ \\
\hline Period*Public Feedback & $\begin{array}{c}-0.230^{* * *} \\
(0.080)\end{array}$ & $\begin{array}{c}-0.273^{* * *} \\
(0.078)\end{array}$ & $\begin{array}{c}-0.273^{* * *} \\
(0.078)\end{array}$ & $\begin{array}{c}-0.273^{* * *} \\
(0.078)\end{array}$ & $\begin{array}{c}-0.273^{* * *} \\
(0.078)\end{array}$ \\
\hline Reciprocity & $\begin{array}{c}0.116 \\
(0.470)\end{array}$ & & & & \\
\hline Effort Priming & & & $\begin{array}{c}0.142 \\
(0.477)\end{array}$ & & \\
\hline Emotion Priming & & & $\begin{array}{c}0.456 \\
(0.367)\end{array}$ & & \\
\hline Agreeableness & & $\begin{array}{c}0.099 \\
(0.139)\end{array}$ & & $\begin{array}{c}0.111 \\
(0.140)\end{array}$ & $\begin{array}{c}0.110 \\
(0.138)\end{array}$ \\
\hline Openness & & $\begin{array}{c}0.204 \\
(0.136)\end{array}$ & & $\begin{array}{c}0.212 \\
(0.137)\end{array}$ & $\begin{array}{l}0.224^{*} \\
(0.135)\end{array}$ \\
\hline Age & & & & $\begin{array}{l}-0.091 \\
(0.077)\end{array}$ & \\
\hline Female & & & & $\begin{array}{l}-0.207 \\
(0.683)\end{array}$ & \\
\hline Social Insecurity & & & & & $\begin{array}{c}0.014 \\
(0.459)\end{array}$ \\
\hline Personal Insecurity & & & & & $\begin{array}{l}-0.747^{*} \\
(0.432)\end{array}$ \\
\hline Developmental Insecurity & & & & & $\begin{array}{l}-0.033 \\
(0.431)\end{array}$ \\
\hline Session Dummies & Yes & Yes & Yes & Yes & Yes \\
\hline 11 & -2045 & -2143 & -2143 & -2142 & -2141 \\
\hline $\mathrm{N}$ & 840 & 5882 & 882 & 882 & 882 \\
\hline
\end{tabular}


Table 7: DYNAMIC INDIVIDUAL PERFORMANCE (FIRST DIFFERENCE POINTS)

The dependent variable is the first difference (i.e. the difference between two periods) in the number of points. Mortality Treatment, Public Feedback, Words Recall Mortality, Words Recall Music, Loss, Math Ability, Agreeableness, Openness and Period are defined in the same way as in Table (5). Rank 1st (t-1) and Rand 2nd (t-1) are dummy variables equal to 1 if the subject respectively ranked 1st or 2 nd in the previous period.

\begin{tabular}{lccccc}
\hline & $\mathrm{a}$ & $\mathrm{b}$ & $\mathrm{c}$ & $\mathrm{d}$ & $\mathrm{e}$ \\
\hline Mortality Treatment & -0.191 & -0.553 & -0.527 & -0.527 & -0.250 \\
& $(0.356)$ & $(0.402)$ & $(0.426)$ & $(0.426)$ & $(0.431)$ \\
Public Feedback & $-0.815^{* *}$ & $-0.755^{* *}$ & $-0.746^{* *}$ & $-0.746^{* *}$ & $-0.825^{* * *}$ \\
& $(0.328)$ & $(0.303)$ & $(0.304)$ & $(0.304)$ & $(0.307)$ \\
Public Feedback*Mortality & 0.493 & 0.483 & 0.475 & 0.475 & 0.572 \\
& $(0.481)$ & $(0.469)$ & $(0.492)$ & $(0.493)$ & $(0.480)$ \\
Rank 1st (t-1) & $-1.232^{* * *}$ & $-1.281^{* * *}$ & $-1.320^{* * *}$ & $-1.322^{* * *}$ & $-1.369^{* * *}$ \\
& $(0.199)$ & $(0.206)$ & $(0.216)$ & $(0.217)$ & $(0.221)$ \\
Rank 2nd (t-1) & $-0.778^{* * *}$ & $-0.797^{* * *}$ & $-0.816^{* * *}$ & $-0.819^{* * *}$ & $-0.836^{* * *}$ \\
& $(0.287)$ & $(0.287)$ & $(0.291)$ & $(0.292)$ & $(0.291)$ \\
Words Recall Mortality & & $0.049^{*}$ & $0.049^{*}$ & $0.049^{*}$ & $0.043^{*}$ \\
& & $(0.025)$ & $(0.025)$ & $(0.025)$ & $(0.025)$ \\
Words Recall Music & & -0.040 & -0.046 & -0.046 & -0.009 \\
& & $(0.059)$ & $(0.060)$ & $(0.060)$ & $(0.060)$ \\
Loss & & & -0.097 & -0.097 & -0.114 \\
& & & $(0.151)$ & $(0.151)$ & $(0.141)$ \\
Math Ability & & & 0.050 & 0.050 & 0.064 \\
& & & $(0.062)$ & $(0.062)$ & $(0.062)$ \\
Period & & & & -0.026 & -0.026 \\
& & & & $(0.047)$ & $(0.047)$ \\
Agreeableness & & & & & 0.018 \\
& & & & & $(0.030)$ \\
Openness & 756 & 756 & 756 & 756 & 756 \\
Constant & & & & & \\
Session Dummies & $1.380^{* * *}$ & $1.484^{* * *}$ & $1.373^{* * *}$ & $1.491^{* * *}$ & 0.430 \\
N & $(0.234)$ & $(0.270)$ & $(0.309)$ & $(0.377)$ & $(0.521)$ \\
\hline \hline
\end{tabular}

${ }^{*} \mathrm{p}<0.10,{ }^{* *} \mathrm{p}<0.05,{ }^{* * *} \mathrm{p}<0.01$ 
Table 8: DYNAMIC INDIVIDUAL PERFORMANCE (RANK)

The dependent variable is individual rank in each period. The lower the rank, the higher the relative position of the individual in the peer group. Mortality Treatment, Public Feedback, Words Recall Mortality, Words Recall Music, Loss, Math Ability, Agreeableness, Openness and Period are defined in the same way as in Table (5). Rank 1st (t-1) and Rand 2nd (t-1) are dummy variables equal to 1 if the subject respectively ranked 1st or 2nd in the previous period.

\begin{tabular}{|c|c|c|c|c|}
\hline & $a$ & $b$ & $c$ & d \\
\hline \multirow{2}{*}{ Mortality Treatment } & -0.038 & 0.100 & -0.115 & -0.115 \\
\hline & (0.172) & $(0.213)$ & $(0.247)$ & $(0.244)$ \\
\hline \multirow{2}{*}{ Public Feedback } & 0.004 & -0.010 & -0.006 & 0.012 \\
\hline & (0.132) & (0.136) & (0.118) & (0.154) \\
\hline \multirow[t]{2}{*}{ Public Feedback*Mortality } & -0.007 & -0.012 & -0.032 & -0.027 \\
\hline & $(0.211)$ & $(0.238)$ & (0.241) & $(0.239)$ \\
\hline \multirow[t]{2}{*}{ Rank 1st (t-1) } & $-0.926^{* * *}$ & $-0.846^{* * *}$ & $-1.021^{* * *}$ & $-1.051^{* * *}$ \\
\hline & $(0.086)$ & $(0.091)$ & $(0.118)$ & $(0.135)$ \\
\hline \multirow{2}{*}{ Rank 2nd (t-1) } & $-0.488^{* * *}$ & $-0.453^{* * *}$ & $-0.639^{* * *}$ & $-0.573^{* * *}$ \\
\hline & $(0.085)$ & $(0.084)$ & $(0.117)$ & (0.149) \\
\hline \multirow[t]{2}{*}{ Words Recall Mortality } & & $-0.031^{* *}$ & $-0.037^{* * *}$ & $-0.037^{* * * *}$ \\
\hline & & $(0.012)$ & $(0.014)$ & $(0.014)$ \\
\hline \multirow[t]{2}{*}{ Words Recall Music } & & 0.006 & 0.006 & 0.007 \\
\hline & & $(0.022)$ & (0.019) & (0.020) \\
\hline \multirow[t]{2}{*}{ Loss } & & 0.070 & 0.091 & 0.095 \\
\hline & & $(0.074)$ & (0.078) & $(0.078)$ \\
\hline \multirow{2}{*}{ Math Ability } & & $-0.066^{* *}$ & $-0.059^{* *}$ & $-0.060^{* *}$ \\
\hline & & $(0.027)$ & $(0.027)$ & $(0.027)$ \\
\hline \multirow[t]{2}{*}{ Period } & & 0.004 & 0.004 & 0.005 \\
\hline & & $(0.012)$ & $(0.012)$ & $(0.012)$ \\
\hline \multirow[t]{2}{*}{ Rank 1st $(\mathrm{t}-1)^{*}$ Mortality } & & & $0.363^{* *}$ & $0.367^{* *}$ \\
\hline & & & (0.169) & (0.168) \\
\hline \multirow[t]{2}{*}{ Rank 2nd (t-1)*Mortality } & & & $0.365^{* *}$ & $0.362^{* *}$ \\
\hline & & & (0.162) & $(0.161)$ \\
\hline Rank 1st (t-1)*Public Feedback & & & & $\begin{array}{c}0.060 \\
(0.165)\end{array}$ \\
\hline Rank 2nd (t-1)*Public Feedback & & & & -0.132 \\
\hline \multirow[t]{2}{*}{ Constant } & $1.448^{* * *}$ & $1.580^{* * *}$ & $1.669^{* * *}$ & $1.656^{* * *}$ \\
\hline & $(0.114)$ & (0.155) & $(0.150)$ & (0.153) \\
\hline Session Dummies & Yes & Yes & Yes & Yes \\
\hline $\mathrm{N}$ & 756 & 756 & 756 & 756 \\
\hline
\end{tabular}




\section{INSTRUCTIONS}

Welcome to LES Lab! This experiment will last about 60 minutes and it is divided into two parts.

In the first part, you will be asked to write a short essay on a specific topic that will appear on your screen. You will have about 10 minutes to write your essay. After that, you will be asked to compare the length of some words. By pressing the button "Right" or "Link" you can choose which word is the longest. Finally, you will undertake a short memory game. You will receive 0.25 cent for each word you will be able to remember in this memory game.

In the second part of this experiment, you will be asked to solve algebraic summations for 7 periods. Each period, you will be part of a group - always different and randomly assigned by the computer - of 3 participants, and you will have 120 seconds to enter the algebraic summation of the two casual numbers appearing on your screen. At the end of each period, you will be personally informed about your results, both in absolute (number of correct answers) and relative terms (compare to the other members of your group). Please note that the result could be First, Second, or Last. After the first period, you will able to see the history of the game by pressing the dedicated button appearing on your screen. [Public Feedback only: On this screen, you can also see the results obtained by your peer-group members in the previous period.]

For each period you will earn 1 euro. You will thus earn in total 7 euro. You are not obliged to enter any summation, and you are allowed - if you wish - to do other activities. For example, you can read the magazines that you have at your desk or the materials you brought with you. You are never allowed to use pens, pencils or calculators, nor to talk with other participants. Should you disregard any of these simple rules, we will be forced to exclude you from the experiment.

At the end of each phase, you will be asked to compile a questionnaire.

Your participation will remain anonymous to the other participants as well as to the experimenter. Your payment will be made through an identification number automatically assigned by the computer.

Rise your hand up, should you have any question. We will privately answer it. Thank you for your participation. 


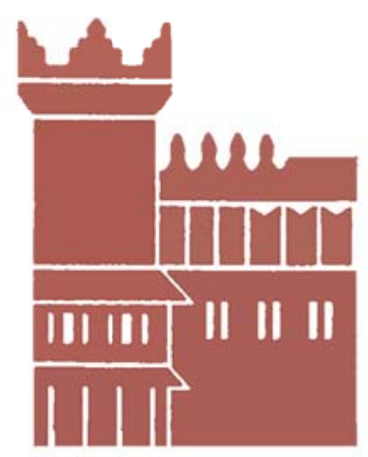

Alma Mater Studiorum - Università di Bologna DEPARTMENT OF ECONOMICS

Strada Maggiore 45

40125 Bologna - Italy

Tel. +39051 2092604

Fax +390512092664

http://www.dse.unibo.it 